\title{
The Influence of Chemical Composition of Commercial Lemon Essential Oils on the Growth of Candida Strains
}

\author{
M. Białoń • T. Krzyśko-Łupicka • \\ M. Koszałkowska $\cdot$ P. P. Wieczorek
}

Received: 24 August 2013/Accepted: 24 December 2013/Published online: 12 January 2014

(C) The Author(s) 2014. This article is published with open access at Springerlink.com

\begin{abstract}
Candida yeasts are saprophytes naturally present in the environment and forming colonies on human mucous membranes and skin. They are opportunistic fungi that cause severe and even fatal infections in immunocompromised individuals. Several essential oils, including eucalyptus, pine, cinnamon and lemon, have been shown to be effective against Candida strains. This study addresses the chemical composition of some commercial lemon essential oils and their antifungal potential against selected Candida yeast strains. Antifungal potential and minimum inhibitory concentrations were determined for six commercial lemon essential oils against five Candida yeast strains (Candida albicans 31, Candida tropicalis 32, Candida glabrata 33, Candida glabrata 35 and Candida glabrata 38). On the basis of the GCMS analysis, it was found that the tested lemon essential oils had different chemical compositions, but mostly, they contained almost exclusively terpenes and oxygenated terpenes. The tests show that antifungal potential of lemon essential oils against Candida yeast strains was related to the high content of
\end{abstract}

M. Białoń $(\bowtie) \cdot$ P. P. Wieczorek

Faculty of Chemistry, University of Opole, Oleska 48, 45-052 Opole, Poland

e-mail: Marietta.Bialon@uni.opole.pl

T. Krzyśko-Łupicka · M. Koszałkowska

Independent Department of Biotechnology and Molecular Biology, Faculty of Natural and Technical Science,

University of Opole, Kominka 6A, 45-035 Opole, Poland monoterpenoids and the type of Candida strains. From six tested commercial oils, only four (ETJA, VeraNord, Avicenna-Oil and Aromatic Art) shows antifungal potential against three Candida species ( $C$. albicans, C. tropicalis and C. glabrata). Vera-Nord and Avicenna-Oil show the best activity and effectively inhibit the growth of the $C$. albicans strain across the full range of the concentrations used. Our study characterises lemon essential oils, which could be used as very effective natural remedies against candidiasis caused by $C$. albicans.

Keywords Candida albicans · Antifungal · Lemon essential oils · GCMS

\section{Introduction}

The interest in natural antimicrobial preparations, such as extracts and essential oils [1-3], has significantly grown in recent years. The biological activity and efficacy of essential oils depend on the quality and quantity of the active substance contained in the raw material $[4,5]$, which in turn depends on the plant variety, genus and quality, growing conditions (climate, soil and fertilisation), time of harvest as well as the way the essential oil is produced and stored. The inhibition of the growth of bacterial and fungal strains is related to volatile compounds contained in essential oils [6] and the sensitivity of microorganisms. 
Candida yeasts are saprophytes naturally present in the environment and forming colonies on human mucous membranes and skin. They are opportunistic fungi that cause severe and even fatal infections in immunocompromised individuals. Several essential oils, including eucalyptus, pine, cinnamon and lemon, have been shown to be effective against Candida strains $[3,5,7]$. However, the reports on the biological activity of lemon essential oil are ambiguous. Some literature data recommend it as highly effective, while other reports that the effects of its use are quite ordinary [7, 8]. Differences in potential fungicidal properties of lemon essential oils may be due to variable qualitative and quantitative composition of individual essential oils and are related to the development stage of the fruit prior to extraction, fruit condition and quality as well as plant growing conditions. According to Fisher and Phillips [9], the content of volatile substances in lemon essential oils may range from 85 to $99 \%$. The qualitative composition - proportions between the content of particular monoterpenes, sesquiterpenes and their oxygenated derivatives-changes as well $[10,11]$. The highest concentration of volatile substances in lemon essential oils is observed in oils produced from medium-ripe fruit [12]. Citrus essential oils are among the oils generally regarded as safe (GRAS) by the US Food and Drug Administration [13].

The aim of the study was to analyse the chemical composition of commercial lemon essential oils (Citrus limonum L.) available on the European market and to evaluate their antifungal potential against selected Candida yeast strains.

\section{Materials and Methods}

Research Material

- Candida yeast strains consist of the following: Candida albicans 31 (C31), Candida tropicalis 32 (C32), Candida glabrata 33 (C33), Candida glabrata 35 (C35) and Candida glabrata 38 (C38). Candida yeast strains were isolated from bronchial secretions and came from the Collection of Polish National Medicines Institute in Warsaw. The yeasts were incubated on medium YPG slants (2 \% Yeast Extract; $2 \%$ Peptone; $2 \%$ Glucose) [14] at $30{ }^{\circ} \mathrm{C}$ for $48 \mathrm{~h}$, washed with Tween 80 water and standardised. The $2 \times 10^{5} \mathrm{CFU} \mathrm{ml}^{-1}$ yeast suspension was used for tests.

- Lemon essential oils (Citrus limonum L) from various countries available on the Polish market: ETJA (ETJA, Elbląg. Poland), Vera-Nord ("VERA-NORD" S.C., Legionowo, Poland), Avicenna-Oil (Avicenna-Oil ${ }^{\circledR}$, Wrocław, Poland), Dufti by Gies (GIES Kerzen GmbH, Glinde, Germany), Aromatic Art (Müller Kerzenfabrik, Straelen, Germany) and Croce Azzurra (CROCE AZZURRA S.N.C., Brescello, Italy) were tested. The activity of essential oil solutions (in water with $0.05 \%$ Tween 80 ) at the final concentration of 0.6 , $1.0,1.6,2.0,2.6$ and $3.0 \%$ was tested.

Gas Chromatography/Mass Spectrometry (GC/MS) Analysis

The analysis of essential oils samples was performed on Gas Chromatograph HP 6890 coupled with mass spectrometry HP 5973A (Hewlett-Packard). Nonpolar capillary column HP-5MS (5\% diphenyl, $95 \%$ dimethylpolysiloxane), with a length of $30 \mathrm{~m}$, internal diameter $0.25 \mathrm{~mm}$ id and film thickness of $0.25 \mu \mathrm{m}$, was used. Helium was used as a carrier gas, and its flow was $1.5 \mathrm{ml} \mathrm{min}^{-1}$. Analyses were performed in the temperature range $60-280{ }^{\circ} \mathrm{C}$, and the heating rate was $10{ }^{\circ} \mathrm{C} \mathrm{min}{ }^{-1}$. The injection volume was $1 \mu \mathrm{l}$ of $1: 50(\mathrm{v} / \mathrm{v})$ solution of citrus essential oils in dichloromethane. The analysis was repeated three times for each sample.

Essential Oil Screening by the Cylinder-Plate Diffusion Method

The bactericidal activity of lemon essential oils with the varying content of terpene compounds against Candida yeast was evaluated by the cylinder-plate diffusion method in four repetitions [15]. The media were inoculated by means of $1-\mathrm{ml}$ standardised yeast suspension $\left(2 \times 10^{5} \mathrm{CFU} \mathrm{ml}^{-1}\right)$. The final concentration of essential oil (in water with $0.05 \%$ Tween 80) was $0.6 \%, 1.0,1.6,2.0,2.6$ and $3.0 \%$. Water with $0.05 \%$ Tween 80 was used as a control. The plates were incubated at $30{ }^{\circ} \mathrm{C}$ for $48 \mathrm{~h}$. The results are given as the mean value of the diameter of the inhibition of microbial growth in $\mathrm{mm}$. The following criteria were assumed: inhibitory effect-when no growth around 
the wells is observed; neutral activity-the growth stopped at the edge of the wells; stimulation-more intense growth around the wells.

\section{Determination of the Minimum Inhibitory \\ Concentration (MIC)}

The minimum concentration of essential oils inhibiting the growth (MIC) of the tested yeast strains was determined by the tube dilution method in a liquid YPG medium containing essential oils at the final concentrations of 0.6, 1.0, 1.6, 2.0, 2.6 and $3.0 \%$. The culture of the tested strains in a liquid YPG medium (without essential oils) was used as a control. The media were inoculated by means of $1 \mathrm{ml}$ standardised yeast suspension $\left(2 \times 10^{5} \mathrm{CFU} \mathrm{ml}{ }^{-1}\right)$. After $48 \mathrm{~h}$ of incubation at $30{ }^{\circ} \mathrm{C}$, the number of viable cells of microorganisms was determined by the cultivation (on a solid YPG medium) method of ten-fold $\left(10^{-1}-10^{-6}\right)$ dilutions of the culture in water with $0.05 \%$ Tween 80 . After incubation, the number of alive microorganisms (not sensitive to the essential oil) was determined. The minimum inhibitory concentration (MIC) was determined for each essential oil concentration and type.

\section{Results}

On the basis of the GCMS analysis, it was found that the tested lemon essential oils had different chemical compositions, but, except the Aromatic Art essential oil, they contained almost exclusively terpenes and oxygenated terpenes. The content of monoterpenes in the tested essential oils is shown in Table 1, monoterpenoids in Table 2 and sesquiterpenes, oxygenated sesquiterpenes and other compounds of the six tested essential oils in Table 3. Figures presented gas chromatograms of tested lemon essential oils: Fig. 1a Vera-Nord, Fig. 1b Avicenna-Oil, Fig. 2a ETJA, Fig. 2b Aromatic Art, Fig. 3a Dufti by Gies, Fig. 3b Croce Azzurra.

ETJA and Avicenna-Oil lemon essential oils contained 20 and 18 terpenes and terpenoides, respectively, and the greatest diversity of this group of

Table 1 Monoterpenes in lemon essential oils

\begin{tabular}{|c|c|c|c|c|c|c|c|c|c|c|c|c|}
\hline & \multicolumn{2}{|l|}{ ETJA } & \multicolumn{2}{|c|}{ Vera-Nord } & \multicolumn{2}{|c|}{ Avicenna-Oil } & \multicolumn{2}{|c|}{ Dufti by Gies } & \multicolumn{2}{|c|}{ Croce Azzurra } & \multicolumn{2}{|c|}{ Aromatic Art } \\
\hline & $\begin{array}{l}\text { Area } \\
(\%)\end{array}$ & SD & $\begin{array}{l}\text { Area } \\
(\%)\end{array}$ & SD & $\begin{array}{l}\text { Area } \\
(\%)\end{array}$ & SD & $\begin{array}{l}\text { Area } \\
(\%)\end{array}$ & SD & $\begin{array}{l}\text { Area } \\
(\%)\end{array}$ & SD & $\begin{array}{l}\text { Area } \\
(\%)\end{array}$ & SD \\
\hline \multicolumn{13}{|c|}{ Aliphatic monoterpenes } \\
\hline B-myrcene & 4.11 & \pm 0.063 & 1.46 & \pm 0.046 & 0 & 0 & 6.94 & \pm 0.093 & 5.42 & \pm 0.026 & 0.37 & \pm 0.017 \\
\hline trans-ocimene & 0.13 & \pm 0.025 & 0.49 & \pm 0.049 & 0 & 0 & 0 & 0 & 0 & 0 & 0 & 0 \\
\hline \multicolumn{13}{|c|}{ Monocyclic monoterpenes } \\
\hline ß-felandrene & 0 & 0 & 0 & 0 & 0 & 0 & 0.40 & \pm 0.013 & 15.03 & \pm 0.092 & 0 & 0 \\
\hline limonene & 48.27 & \pm 0.048 & 23.39 & \pm 0.054 & 42.03 & \pm 0.124 & 63.20 & \pm 0.007 & 38.50 & \pm 0.074 & 22.42 & \pm 0.017 \\
\hline$\alpha$-terpinene & 0.40 & \pm 0.121 & 0.12 & \pm 0.016 & 0 & 0 & 0 & 0 & 0.14 & \pm 0.032 & 0 & 0 \\
\hline$\gamma$-terpinene & 4.85 & \pm 0.057 & 5.87 & \pm 0.015 & 0 & 0 & 4.78 & \pm 0.087 & 0.16 & \pm 0.013 & 0 & 0 \\
\hline terpinolene & 1.19 & \pm 0.027 & 0.30 & \pm 0.038 & 0 & 0 & 0.34 & \pm 0.046 & 0.04 & \pm 0.004 & 0 & 0 \\
\hline \multicolumn{13}{|c|}{ Bi- and tricyclic monoterpenes } \\
\hline bornylene & 0 & 0 & 0 & 0 & 0.49 & \pm 0.048 & 0 & 0 & 0 & 0 & 0 & 0 \\
\hline camphene & 0.35 & \pm 0.038 & 0 & 0 & 0.17 & \pm 0.014 & 0 & 0 & 0 & 0 & 0 & 0 \\
\hline 3-carene & 0 & 0 & 0 & 0 & 0 & 0 & 0.16 & \pm 0.027 & 0 & 0 & 0 & 0 \\
\hline$\alpha$-pinene & 11.06 & \pm 0.135 & 1.44 & \pm 0.012 & 3.42 & \pm 0.026 & 3.61 & \pm 0.110 & 5.56 & \pm 0.082 & 0.16 & \pm 0.024 \\
\hline B-pinene & 15.14 & \pm 0.038 & 8.93 & \pm 0.035 & 15.15 & \pm 0.057 & 14.31 & \pm 0.163 & 19.98 & \pm 0.097 & 2.21 & \pm 0.068 \\
\hline 3-thujene & 0 & 0 & 0.30 & \pm 0.036 & 0.22 & \pm 0.013 & 0.33 & \pm 0.037 & 1.25 & \pm 0.067 & 0 & 0 \\
\hline sabinene & 0 & 0 & 0.65 & \pm 0.093 & 0 & 0 & 0 & 0 & 0 & 0 & 0.10 & \pm 0.026 \\
\hline tricyclene & 0.21 & \pm 0.037 & 0 & 0 & 0 & 0 & 0 & 0 & 0 & 0 & 0 & 0 \\
\hline Monoterpenes & 85.70 & & 42.96 & & 61.49 & & 94.07 & & 86.07 & & 25.27 & \\
\hline
\end{tabular}

$S D$ standard deviation 
Table 2 Oxygenated monoterpenes in lemon essential oils

\begin{tabular}{|c|c|c|c|c|c|c|c|c|c|c|c|c|}
\hline & \multicolumn{2}{|l|}{ ETJA } & \multicolumn{2}{|c|}{ Vera-Nord } & \multicolumn{2}{|c|}{ Avicenna-Oil } & \multicolumn{2}{|c|}{ Dufti by Gies } & \multicolumn{2}{|c|}{ Croce Azzurra } & \multicolumn{2}{|c|}{ Aromatic Art } \\
\hline & $\begin{array}{l}\text { Area } \\
(\%)\end{array}$ & SD & $\begin{array}{l}\text { Area } \\
(\%)\end{array}$ & SD & $\begin{array}{l}\text { Area } \\
(\%)\end{array}$ & SD & $\begin{array}{l}\text { Area } \\
(\%)\end{array}$ & SD & $\begin{array}{l}\text { Area } \\
(\%)\end{array}$ & SD & $\begin{array}{l}\text { Area } \\
(\%)\end{array}$ & SD \\
\hline \multicolumn{13}{|c|}{ Oxygenated aliphatic monoterpenes } \\
\hline $\begin{array}{l}\text { citral (mix of } \\
\text { isomers) }\end{array}$ & 0 & 0 & 0.23 & \pm 0.009 & 0.70 & \pm 0.017 & 1.06 & \pm 0.028 & 2.63 & \pm 0.034 & 0 & 0 \\
\hline trans-citral & 7.14 & \pm 0.067 & 15.52 & \pm 0.042 & 0 & 0 & 0 & 0 & 0.16 & \pm 0.015 & 0.36 & \pm 0.031 \\
\hline cis-citral & 4.30 & \pm 0.140 & 19.41 & \pm 0.021 & 0 & 0 & 0.30 & \pm 0.060 & 1.54 & \pm 0.011 & 0 & 0 \\
\hline citronellal & 0.20 & \pm 0.024 & 0 & 0 & 0 & 0 & 0.70 & \pm 0.050 & 0.29 & \pm 0.070 & 0 & 0 \\
\hline geranyl acetate & 0.91 & \pm 0.012 & 0.59 & \pm 0.020 & 0 & 0 & 0 & 0 & 0 & 0 & 0 & 0 \\
\hline cis-geraniol & 0 & 0 & 4.96 & \pm 0.033 & 0 & 0 & 0 & 0 & 0 & 0 & 0 & 0 \\
\hline trans-geraniol & 0 & 0 & 3.39 & \pm 0.036 & 1.58 & \pm 0.017 & 0 & 0 & 0 & 0 & 0 & 0 \\
\hline Linalool & 0.29 & \pm 0.063 & 0 & 0 & 0.63 & \pm 0.058 & 1.73 & \pm 0.059 & 1.51 & \pm 0.057 & 0 & 0 \\
\hline linalyl propanoate & 0 & 0 & 0.25 & \pm 0.037 & 0 & 0 & 0.24 & \pm 0.039 & 0 & 0 & 0 & 0 \\
\hline bergamol & 0 & 0 & 0 & 0 & 0 & 0 & 0 & 0 & 0 & 0 & 9.53 & \pm 0.071 \\
\hline neryl acetate & 0.49 & \pm 0.061 & 0.42 & \pm 0.052 & 0 & 0 & 0.16 & \pm 0.047 & 1.14 & \pm 0.092 & 0.21 & \pm 0.081 \\
\hline \multicolumn{13}{|c|}{ Oxygenated monocyclic monoterpenes } \\
\hline trans-carveol & 0 & 0 & 0 & 0 & 3.36 & \pm 0.052 & 0 & 0 & 0 & 0 & 0 & 0 \\
\hline carvone & 0 & 0 & 0 & 0 & 7.28 & \pm 0.032 & 0.10 & \pm 0.003 & 0 & 0 & 0 & 0 \\
\hline $\begin{array}{l}\text { trans-p-2,8- } \\
\text { mentadien-1-ol }\end{array}$ & 0 & 0 & 0 & 0 & 1.84 & \pm 0.046 & 0 & 0 & 0 & 0 & 0 & 0 \\
\hline menthol & 0,12 & $\pm 0,006$ & 0 & 0 & 0 & 0 & 0 & 0 & 0 & 0 & 0 & 0 \\
\hline menthone & 0,06 & $\pm 0,029$ & 0 & 0 & 0 & 0 & 0 & 0 & 0 & 0 & 0 & 0 \\
\hline 1-terpinen-4-ol & 0 & 0 & 0 & 0 & 5.57 & \pm 0.075 & 0 & 0 & 0.42 & \pm 0.013 & 0 & 0 \\
\hline \multicolumn{13}{|c|}{ Oxygenated bi- and tricyclic monoterpenes } \\
\hline pinene oxide & 0.17 & \pm 0.016 & 0 & 0 & 0 & 0 & 0.65 & \pm 0.050 & 0 & 0 & 0 & 0 \\
\hline pinocarveol & 0 & 0 & 0 & 0 & 5.44 & \pm 0.035 & 0 & 0 & 0 & 0 & 0 & 0 \\
\hline verbenol & 0.08 & \pm 0.013 & 0 & 0 & 4.90 & \pm 0.024 & 0 & 0 & 0 & 0 & 0 & 0 \\
\hline trans-verbenol & 0 & 0 & 0 & 0 & 1.50 & \pm 0.038 & 0 & 0 & 0 & 0 & 0 & 0 \\
\hline $\begin{array}{l}\text { Oxygenated } \\
\text { monoterpenes }\end{array}$ & 13.76 & & 44.76 & & 32.80 & & 4.93 & & 7.67 & & 10.09 & \\
\hline
\end{tabular}

$S D$ standard deviation

compounds was observed in Croce Azzurra and VeraNord essential oils (23 compounds). Limonene was present in the tested essential oils in the largest amounts-in essential oils of the German company Dufti (63.2\%), ETJA (48.3\%), Avicenna-Oil $(42.0 \%)$ and the Italian company Croce Azzurra $(38.5 \%)$. The type and percentage composition of other compounds were also different in all tested lemon essential oils and were characteristic for particular producers. The following compounds were additionally present in the essential oil of the German company Dufti: $\beta$-pinene $(14.3 \%), \quad \beta$-myrcene $(6.9 \%), \gamma$-terpinene $(4.8 \%)$ and $\alpha$-pinene $(3.6 \%)$
(Fig. 3a, Table 1). In the ETJA essential oil, other main compounds were $\beta$-pinene (15.1\%), $\alpha$-pinene $(11.1 \%)$, citral and its isomers $(11.4 \%$ in total), $\gamma$ terpinene $(4.8 \%)$ and $\beta$-myrcene $(4.1 \%$ ) (Fig. $2 \mathrm{a}$, Table 1). Avicenna-Oil included $\beta$-pinene (15.2\%), carvone (7.3\%), 1-terpinen-4-ol (5.6\%), pinocarveol $(5.4 \%)$ and verbenol (4.9\%) (Fig. 1b, Tables 1, 2). The lemon essential oil of the Italian company Croce Azzurra contained large amounts of $\beta$-pinene $(20.0 \%), \beta$-felandrene $(15.0 \%), \alpha$-pinene $(5.6 \%)$ and $\beta$-myrcene (5.4\%) (Fig. 3b, Table 1). Citral and its isomers (35.1\% in total), limonene $(23.4 \%)$, oraz $\beta$ pinene (8.9\%), cis-, trans-geraniol (8.4\% in total), 
Table 3 Sesquiterpenes, oxygenated sesquiterpenes and others compounds in lemon essential oils

\begin{tabular}{|c|c|c|c|c|c|c|c|c|c|c|c|c|}
\hline & \multicolumn{2}{|l|}{ ETJA } & \multicolumn{2}{|c|}{ Vera-Nord } & \multicolumn{2}{|c|}{ Avicenna-Oil } & \multicolumn{2}{|c|}{ Dufti by Gies } & \multicolumn{2}{|c|}{ Croce Azzurra } & \multicolumn{2}{|c|}{ Aromatic Art } \\
\hline & $\begin{array}{l}\text { Area } \\
(\%)\end{array}$ & SD & $\begin{array}{l}\text { Area } \\
(\%)\end{array}$ & SD & $\begin{array}{l}\text { Area } \\
(\%)\end{array}$ & SD & $\begin{array}{l}\text { Area } \\
(\%)\end{array}$ & SD & $\begin{array}{l}\text { Area } \\
(\%)\end{array}$ & SD & $\begin{array}{l}\text { Area } \\
(\%)\end{array}$ & SD \\
\hline \multicolumn{13}{|l|}{ Sesquiterpenes } \\
\hline$\alpha$-bergamotene & 0 & 0 & 0.95 & \pm 0.078 & 2.31 & \pm 0.130 & 0 & 0 & 0.89 & \pm 0.057 & 0 & 0 \\
\hline B-bergamotene & 0 & 0 & 0 & 0 & 0 & 0 & 0 & 0 & 1.54 & \pm 0.062 & 0 & 0 \\
\hline ß-bisabolene & 0 & 0 & 0.48 & \pm 0.097 & 0 & 0 & 0 & 0 & 1.82 & \pm 0.058 & 0 & 0 \\
\hline$\alpha$-cadinene & 0 & 0 & 0 & 0 & 0 & 0 & 0.13 & \pm 0.011 & 0 & 0 & 0 & 0 \\
\hline B-cadinene & 0 & 0 & 0 & 0 & 0 & 0 & 0.09 & \pm 0.008 & 0 & 0 & 0 & 0 \\
\hline calarene & 0 & 0 & 0 & 0 & 0 & 0 & 0.15 & \pm 0.011 & 0 & 0 & 0 & 0 \\
\hline caryophyllene & 0 & 0 & 0.24 & \pm 0.078 & 0 & 0 & 0.29 & \pm 0.091 & 1.11 & \pm 0.041 & 0.12 & \pm 0.011 \\
\hline$\alpha$-caryophyllene & 0 & 0 & 6.09 & \pm 0.084 & 0 & 0 & 0 & 0 & 0.06 & \pm 0.031 & 0 & 0 \\
\hline ß-farnesene & 0 & 0 & 0 & 0 & 0 & 0 & 0 & 0 & 0.06 & \pm 0.006 & 0 & 0 \\
\hline germacene B & 0 & 0 & 0 & 0 & 0 & 0 & 0 & 0 & 0.38 & \pm 0.009 & 0 & 0 \\
\hline valencene & 0 & 0 & 0 & 0 & 0 & 0 & 0.32 & \pm 0.008 & 0 & 0 & 0 & 0 \\
\hline Sesquiterpenes & 0 & & 7.76 & & 2.31 & & 0.98 & & 5.84 & & 0.12 & \\
\hline \multicolumn{13}{|c|}{ Oxygenated sesquiterpenes } \\
\hline caryophyllene oxide & 0 & 0 & 0 & 0 & 3.20 & \pm 0.051 & 0 & 0 & 0 & 0 & 0 & 0 \\
\hline farnesol & 0 & 0 & 4.48 & \pm 0.058 & 0 & 0 & 0 & 0 & 0 & 0 & 6.12 & \pm 0.119 \\
\hline $\begin{array}{l}\text { Oxygenated } \\
\text { sesquiterpenes }\end{array}$ & 0 & & 4.48 & & 3.20 & & 0 & & 0 & & 6.12 & \\
\hline \multicolumn{13}{|l|}{ Others } \\
\hline hexanoic acid & 0 & 0 & 0 & 0 & 0 & 0 & 0 & 0 & 0 & 0 & 0.47 & \pm 0.132 \\
\hline hydrocinnamic acid & 0 & 0 & 0 & 0 & 0 & 0 & 0 & 0 & 0 & 0 & 6.54 & \pm 0.698 \\
\hline ß-ionene & 0 & 0 & 0 & 0 & 0 & 0 & 0 & 0 & 0 & 0 & 7.81 & \pm 0.414 \\
\hline isopropyl myristate & 0 & 0 & 0 & 0 & 0 & 0 & 0 & 0 & 0 & 0 & 42.78 & \pm 0.422 \\
\hline $\begin{array}{l}\text { 1,1-dimethoxy-2- } \\
\text { phenylopropane }\end{array}$ & 0 & 0 & 0 & 0 & 0 & 0 & 0 & 0 & 0 & 0 & 0.36 & \pm 0.031 \\
\hline Others & 0 & & 0 & & 0 & & 0 & & 0 & & 57.60 & \\
\hline
\end{tabular}

SD standard deviation

caryophyllene $(6.4 \%), \gamma$-terpinene $(5.9 \%)$ and farnesol (4.5\%) (Fig. 1a, Tables 1, 2, 3) were present in the Vera-Nord essential oil in the largest amounts. The main ingredient of the Aromatic Art essential oil was isopropyl myristate $(42.8 \%), \beta$-ionene $(7.8 \%)$, hydrocinnamic acid $(6.5 \%)$ and 10 terpenes, and oxygenated terpenes-mainly limonene (22.4\%), bergamol $(9.5 \%)$, farnesol $(6.1 \%)$ and $\beta$-pinene (2.2\%) (Fig. 2b, Tables 1, 2, 3)-accounted for only $41.6 \%$ of the oil composition. The large amount of fatty acid ester (isopropyl myristate) was the reason that not good separation and not symmetrical peaks were achieved in this case, because the chromatographic method typically used for the separation of terpenes and terpenoids (non-polar column) is useless for fatty compounds (Fig. 2b).
Despite the fact that all tested lemon essential oils contained limonene, their impact on the growth of the tested Candida yeasts was different. The Dufti essential oil, although contained the largest amounts of limonene, did not inhibit the growth of any of the tested yeast strains. The Croce Azzurra essential oil also proved to be ineffective as far as the inhibition of the growth of the tested strains is concerned. Therefore, the inhibitory effect of essential oils does not depend on the concentration of limonene but on the presence of other biologically active substances and the sensitivity of yeasts. C. glabrata and C. tropicalis strains are much less sensitive than the $C$. albicans strain. Thus, only some essential oils at higher concentrations exhibit the antifungal potential against these yeast strains. C. glabrata 33 and C. glabrata 35 
Fig. 1 Gas chromatogram of most effective oils: a Vera-Nord lemon essential oil, b Avicenna-Oil lemon essential oil
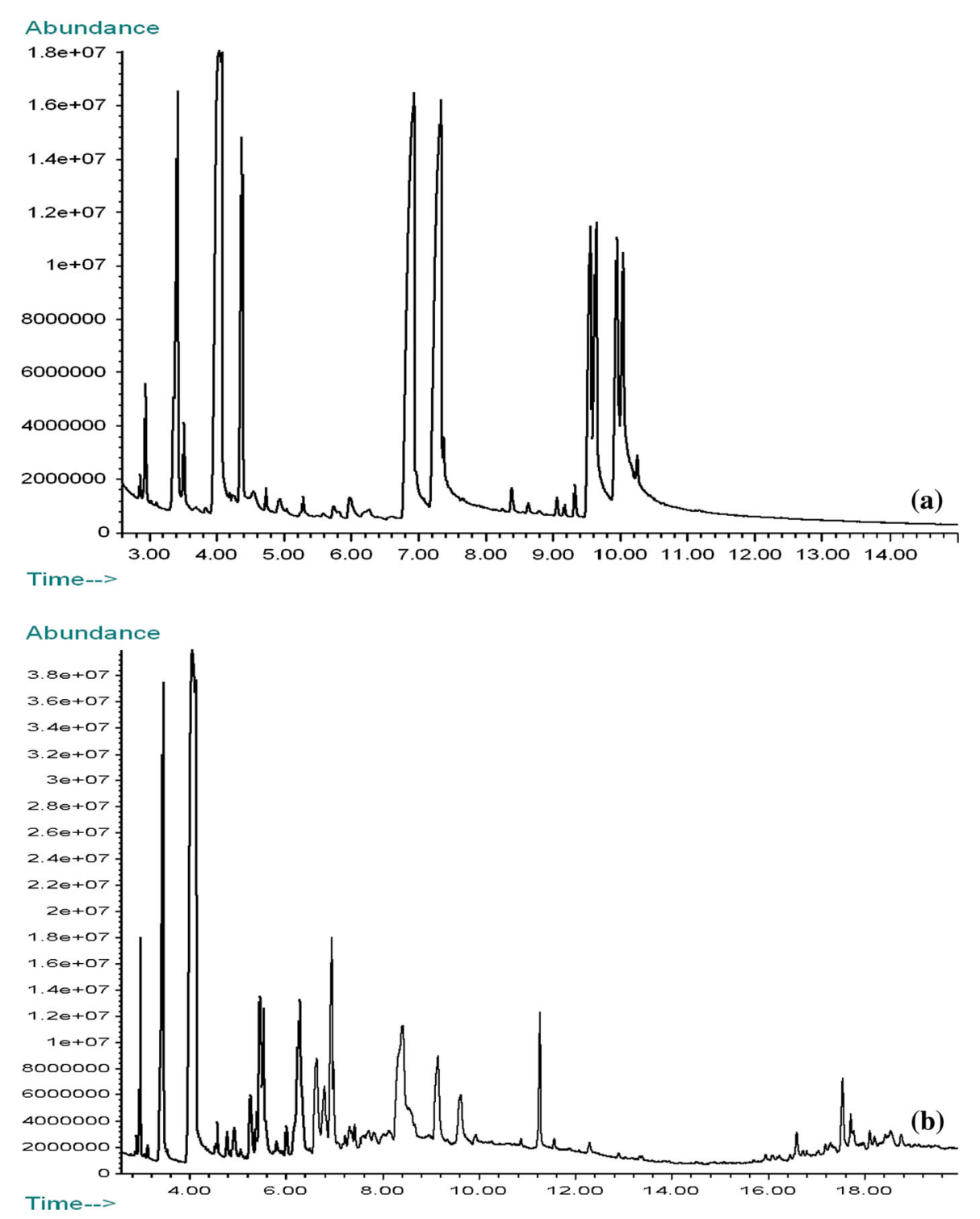

strains were the most resistant to the tested lemon essential oils (none of the tested products inhibited their growth). The effects of the essential oil activity against the tested yeast strains are shown in Table 4.

The tests show that essential oils containing larger amounts of oxygenated monoterpenes have much better antimicrobial properties. Vera-Nord and Avicenna-Oil essential oils contain 44.8 and $32.8 \%$ of monoterpenoids, respectively, and most effectively inhibit the growth of the Candida strain across the full range of the concentrations used. The measured zones of inhibition for Candida albicans 31, depending on the concentration of these essential oils, were from
$23 \mathrm{~mm}$ to complete inhibition-45 $\mathrm{mm}$ (Table 4). Furthermore, it may be concluded that antifungal properties are observed only in the case of essential oils containing more than $10 \%$ of oxygenated monoterpenes. With the lower content of monoterpenoids, the inhibition of the Candida strain growth was observed only for the highest concentrations when ETJA and Aromatic Art essential oils were used. The Aromatic Art essential oil inhibited the growth of $C$. albicans only at the highest concentration of $3 \%$, and the zone of inhibition measured approximately $17 \mathrm{~mm}$. The growth of $C$. glabrata 38 was inhibited by ETJA and Avicenna-Oil essential oils (approximately $45 \mathrm{~mm}$ ) 
Fig. 2 Gas chromatogram of effective oils: a ETJA lemon essential oil, b Aromatic Art lemon essential oil

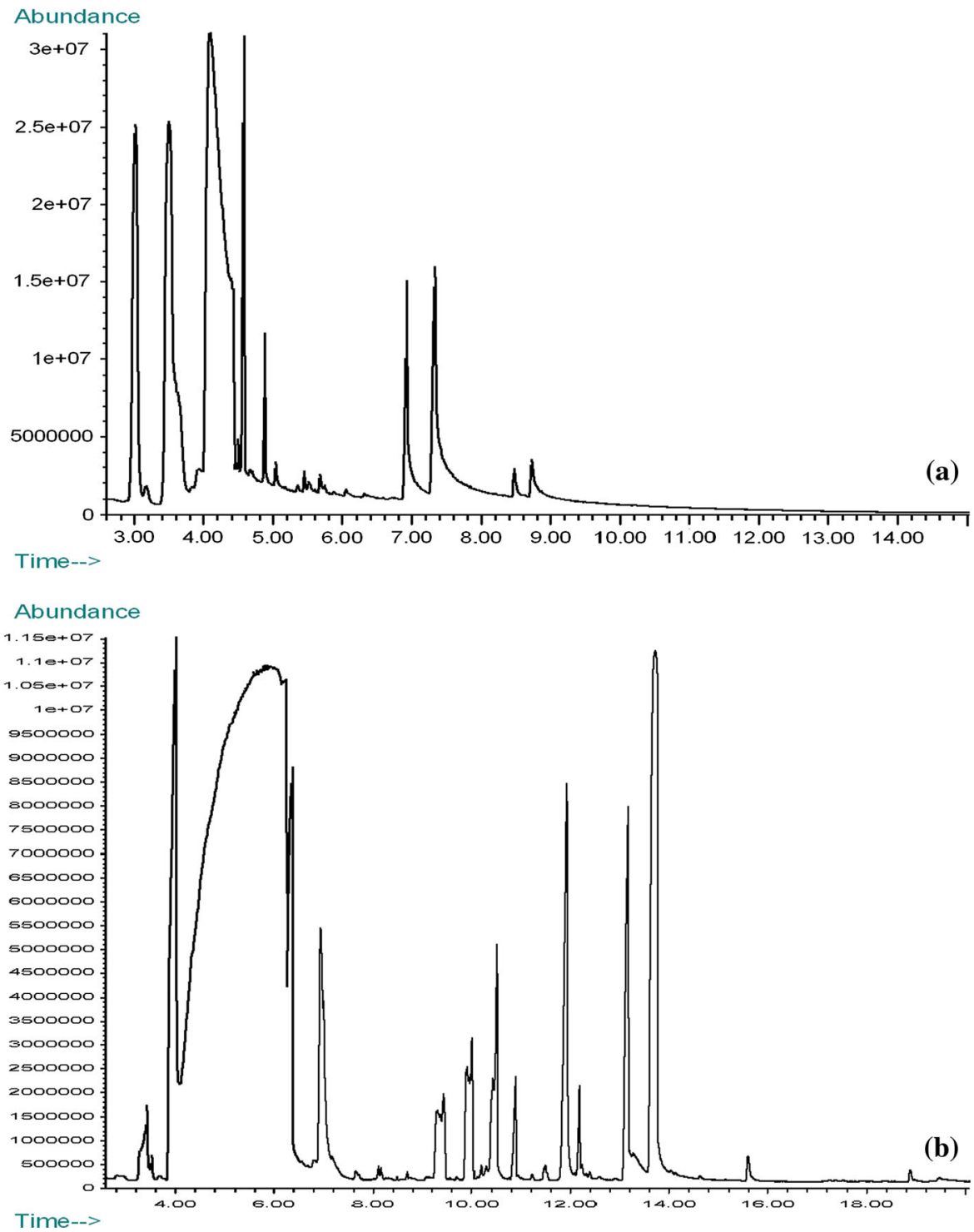

at the concentration of 2.6 and $3 \%$. The $C$. tropicalis 32 strain was sensitive only to the Vera-Nord essential oil at concentrations of 2.6 and $3 \%$. The zones of inhibition measured $15.3 \mathrm{~mm}( \pm 0.40)$ and $16.3 \mathrm{~mm}$ ( \pm 0.40$)$, respectively.

Not only the high content of monoterpenoids but also the presence of particular active ingredients and maintaining adequate proportions between these ingredients is necessary for lemon essential oils to exhibit antimicrobial properties. High antimicrobial activity of the Vera-Nord essential oil is probably due to cis- and trans-citral isomers present in this essential oil in the largest amounts as compared to all essential oils tested. Additionally, the activity of citral present in this essential oil is enhanced by isomers of geraniol and $\gamma$-terpinene. All these compounds are known for their fungicidal properties. Antimicrobial properties of Avicenna-Oil and ETJA essential oils may be due to the synergistic effect of citral and verbenol. However, the proportions of these terpenoides are different depending on the oil, namely, the ETJA essential oil contained $11.4 \%$ of citral isomers and trace amounts of verbenol $(0.1 \%)$. The proportions of these ingredients in the Avicenna-Oil essential oil are reversed: it contains small amounts of citral $(0.7 \%)$ and quite significant amounts of verbenol $(6.4 \%)$. Antifungal potential may be enhanced by terpenoides, such as 
Fig. 3 Gas chromatogram of ineffective oils: a Dufti by Gies lemon essential oil, b Croce Azzurra lemon essential oil

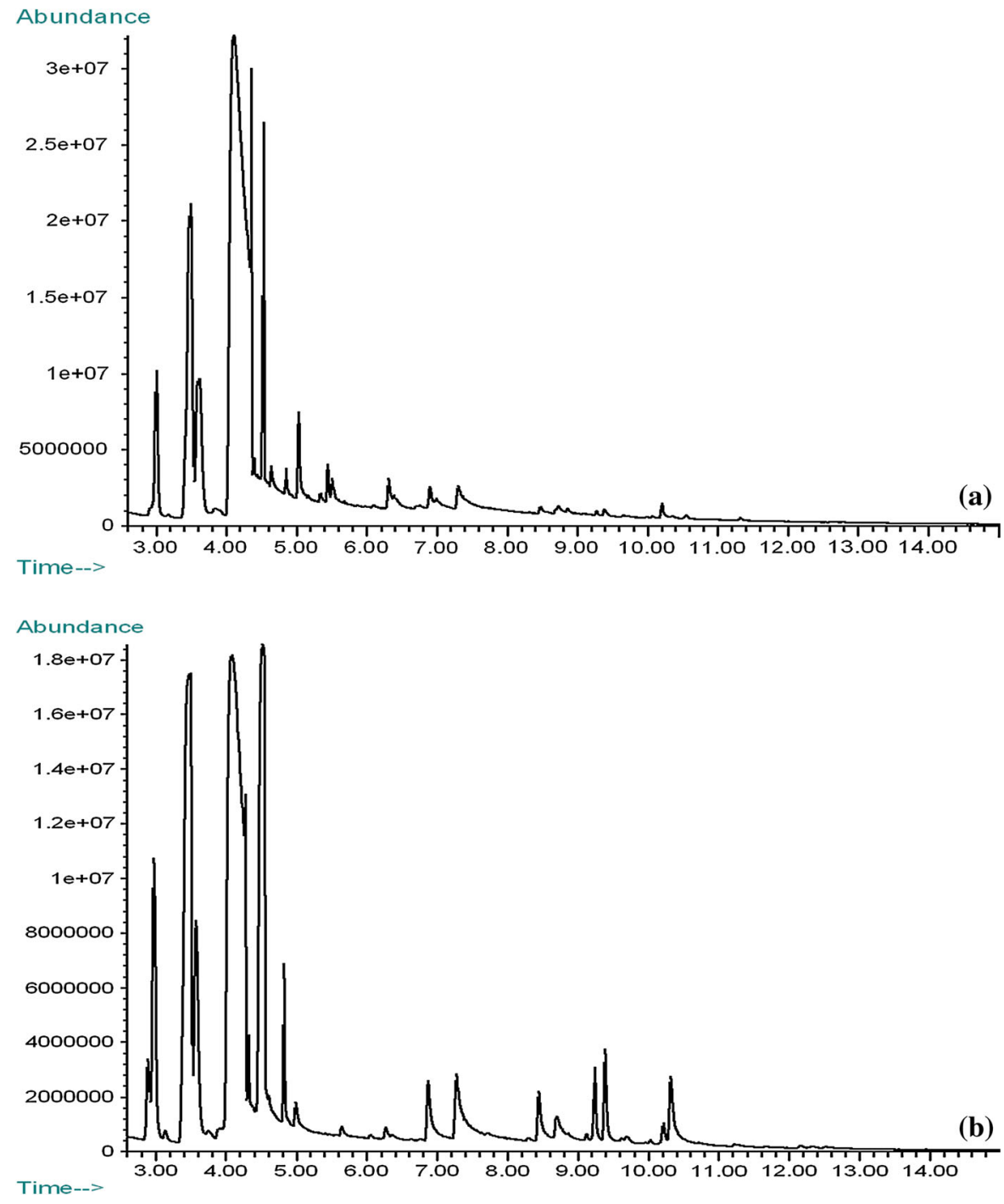

carvone $(7.3 \%)$ or 1-terpinen-4-ol (5.6\%), present in the Avicenna-Oil essential oil.

The chemical composition of the Aromatic Art lemon essential oil differs considerably from the chemical composition of other essential oils tested. This oil inhibits the growth of C. albicans C31 only in small degree.

The MIC of lemon essential oil causing total growth inhibition was determined only for $C$. albicans 31 in the case of Vera-Nord and Avicenna-Oil essential oils. The obtained MIC value was $0.6 \%$, the minimum concentrations of essential oils used. Other essential oils reduced the survival rate of the selected Candida strains by $50-98 \%$.

\section{Discussion}

Reports on the antifungal potential of lemon essential oil against Candida yeasts are ambiguous [5, 7, 8]. Devkatte et al. [7] obtained the MIC value of $0.5 \%$ and the average zone of inhibition of approximately $17.5 \mathrm{~mm}$ for the lemon essential oil tested by them, while the zones of inhibition for the selected Candida strains determined by Warnke et al. [8] measured 16-43 $\mathrm{mm}$. Higher mean values related to the zones of inhibition for C. albicans, ranging from 23 to $45 \mathrm{~mm}$, may be due to the differences in diffusion of particular essential oil ingredients in agar [7,9] and the concentration of biologically active substances, 
Table 4 Inhibitory activity of lemon essential oil
Oil and concentration

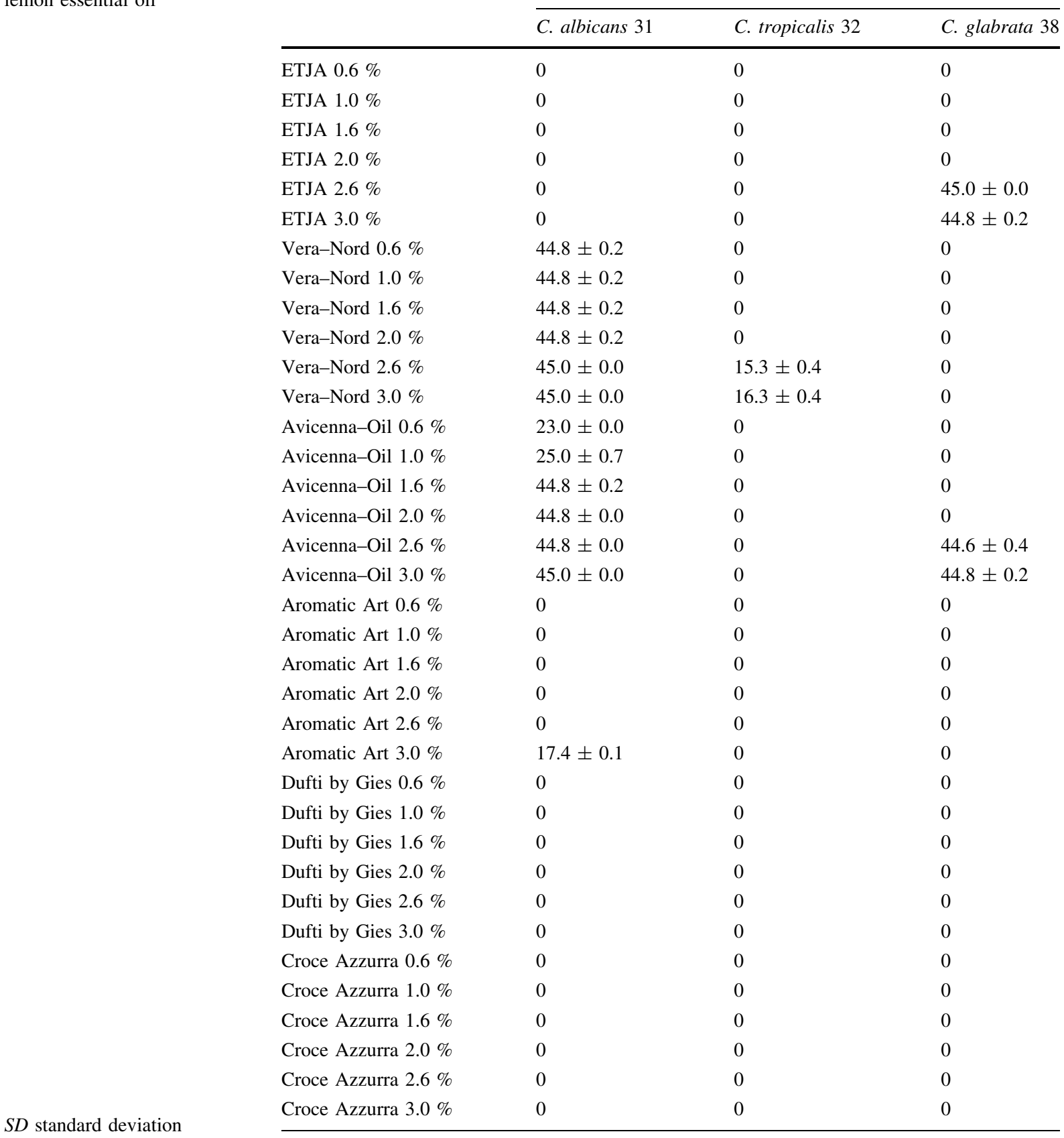

mainly citral, geraniol and verbenol. Thus, when evaluating the essential oils produced from a particular plant, it is good to know their chemical composition. According to many authors, the essential oil volatile phase composition depends on the conditions in which the plant has grown, its development stage and the way it is stored [9]. In the case of citrus fruits, climatic conditions and the region of origin of the fruit are important [11].

Limonene-a monocyclic terpene-was the main ingredient of the tested lemon essential oils. However, the antimicrobial activity depended on the content of oxygenated monoterpenes-the higher the content, the better fungicidal effects were observed. This is 
confirmed by the literature data $[11,13]$. Vera-Nord and Avicenna-Oil essential oils contain 44.8 and $32.8 \%$ of oxygenated monoterpenes, respectively, and exhibit antifungal potential against $C$. albicans across the full range of the concentrations used and may be used as antifungal preparations against this yeast strain. The Aromatic Art essential oil, which is less effective as far as the inhibition of the growth of $C$. albicans is concerned, contains hydrocinnamic acid and bergamol-compounds known for their antimicrobial properties [9, 11].

Candida glabrata and Candida tropicalis strains were less sensitive to the tested essential oils than the C. albicans strain - their growth was inhibited by essential oils used at higher concentrations. The VeraNord essential oil contains significant amounts of cisand trans-citral isomers or geraniol and $\gamma$-terpinene known for their fungicidal properties [9, 11].

The growth of $C$. glabarata 38 was inhibited by two lemon essential oils: Avicenna-Oil and ETJA, which both contains citral and verbenol. Essential oils exhibit antifungal properties when they contain, at the same time, large amounts of one of these oxygenated monoterpenes and small amounts of the second one.

The tested essential oils contained also other valuable ingredients, such as carvone, 1-terpinen-4ol and $\gamma$-terpinene-all of these compounds also exhibit antifungal potential, which has already been described in the literature $[8,9,11,13]$.

The use of lemon essential oils in all kinds of candidiasis seems to be an interesting solution because of their documented safety. It should also be noted that some of the authors at the same time emphasise that it is necessary to conduct tests on the toxicity and possible allergenic effects of selected essential oils [7]. Therefore, understanding the relationship between the chemical composition of essential oils and their antimicrobial activity is of great importance due to the potential use of lemon essential oil-based products as natural remedies against candidiasis caused by $C$. albicans.

\section{Conclusions}

- Lemon essential oils with high content of monoterpenoids may be an ingredient of products against candidiasis caused by Candida.
- Avicenna-Oil and ETJA contain citral and verbenol. Large amounts of one of these oxygenated monoterpenes and small amounts of the second one, at the same time, may be the reason for the growth inhibition of the tested C. glabarata yeasts.

- Antifungal potential of the Aromatic Art essential oil at higher concentrations is probably the result of the synergistic interaction between hydrocinnamic acid and bergamol.

Open Access This article is distributed under the terms of the Creative Commons Attribution License which permits any use, distribution, and reproduction in any medium, provided the original author(s) and the source are credited.

\section{References}

1. Leven M, Vanden Berghe DA, Mertens F, Vlietinck A, Lammens E. Screening of higher plants for biological activities. I. Antimicrobial activity. Planta Med. 1979;36:311-21.

2. Álvarez-Ordóñez A, Carvajal A, Arguello H, et al. Antibacterial activity and mode of action of a commercial citrus fruit extract. J Appl Microbiol. 2013;115:50-60.

3. Hsu CC, Lai WL, Chuang KC, Lee MH, Tsai YC. The inhibitory activity of linalool against the filamentous growth and biofilm formation in Candida albicans. Med Mycol. 2013;51:473-82.

4. Kim KS, Kim YS, Han I, Kim MH, Jung MH. Quantitative and qualitative analyses of the cell death process in Candida albicans treated by antifungal agents. PLoS ONE. 2011; 6(12):e28176.

5. Carvalhinho S, Costa AM, Coelho AC, Martins E, Sampaio A. Susceptibilities of Candida albicans mouth isolates to antifungal agents. Essential oils and mouth rinses. Mycophatologia. 2012;174:69-76.

6. Holley RA, Patel D. Improvement in shelf-life and safety of perishable foods by plant essential oils and smoke antimicrobials. Food Microbiol. 2005;22:273-92.

7. Devkatte AN, Zore GB, Karuppayil SM. Potential of plant oils as inhibitors of Candida albicans growth. FEMS Yeast Res. 2005;5:867-73.

8. Warnke PH, Becker ST, Podschun R, et al. The battle against multi-resistant strains: renaissance of antimicrobial essential oils as a promising force to fight hospital-acquired infections. J Cranio-Maxillofac Surg. 2009;37:392-7.

9. Fisher K, Phillips C. Potential antimicrobial uses of essential oils in food: is citrus the answer? Trends Food Sci Technol. 2008;19:156-64.

10. Moufida S, Marzouk B. Biochemical characterization of blood orange, sweet orange, lemon, bergamot and bitter orange. Phytochemistry. 2003;62:1283-9.

11. Settanni L, Palazzolo E, Guarrasi V, et al. Inhibition of foodborne pathogen bacteria by essential oils extracted from citrus fruits cultivated in Sicily. Food Control. 2012;26:326-30. 
12. Tirado CB, Stashenko EE, Combariza MY, Martinez JR. Comparative study of Colombian citrus oils by high-resolution gas chromatography and gas chromatography-mass spectrometry. J Chromatogr A. 1995;697:501-13.

13. Espina L, Somolinos M, Lorán S, et al. Chemical composition of commercial citrus fruit essential oils and evaluation of their antimicrobial activity acting alone or in combined processes. Food Control. 2011;22:896-902.
14. Difco manual. Dehydrated culture media and reagents for microbiology. Difco Laboratories, Detroit, Michigan, 48232 USA. 10th ed., 1984.

15. Jorgensen JH, Turnidge JD. Suseptility test methods: Dilution and disk diffusion methods. In Murray PR (ed) Manual of Clinical Microbiology, 5th ed. New York: ASM International; 2003. p. 1108-1127. 